\title{
STUDY ON CYCLONE INDUCED PHYTOPLANKTON BLOOM IN THE ARABIAN SEA THROUGH GAP-FREE RECONSTRUCTED CHLOROPHYLL-A DATA
}

\author{
Rebekah Shunmugapandi ${ }^{1, *}$, Shirishkumar Gedam ${ }^{1}$, Arun B Inamdar ${ }^{1}$ \\ ${ }^{1}$ Center of Studies in Resources Engineering, Indian Institute of Technology Bombay, Mumbai, India- \\ (rebekah.s,shirish,abi)@iitb.ac.in
}

KEY WORDS: Arabian Sea, Chlorophyll- $a$ Concentration, DINEOF, Tropical Cyclone, Phytoplankton bloom

\begin{abstract}
Ocean surface phytoplankton responses to the tropical cyclone (TC)/storms have been extensively studied using satellite observations by aggregating the data into a weekly or bi-weekly composite. The reason behind is the significant limitations found in the satellite-based observation is the missing of valid data due to cloud cover, especially at the time of cyclone track passage. The data loss during the cyclone is found to be a significant barrier to efficiently investigate the response of chl- $a$ and SST during cyclone track passage. Therefore it is necessary to rectify the above limitation to effectively study the impact of TC on the chlorophyll- $a$ concentration (chl- $a$ ) and the sea surface temperature (SST) to achieve a complete understanding of their response to the TC prevailed in the Arabian Sea. Intending to resolve the limitation mentioned above, this study aims to reconstruct the MODISAqua chl- $a$, and SST data using Data Interpolating Empirical Orthogonal Function (DINEOF) for all the 31 cyclonic events occurred in the Arabian Sea during 2003-2018 (16 years). Reconstructed satellite retrieved data covering all the cyclonic events were further used to investigate the chl- $a$ and SST dynamics during TC. From the results, the exciting fact has been identified that only two TC over the eastern-AS were able to induce phytoplankton bloom. On investigating this scenario using sea surface temperature, it was disclosed that the availability of nutrients decides the suitable condition for the phytoplankton to proliferate in the surface ocean. Relevant to the precedent criterion, the results witnessed that the 2 TC (Phyan and Ockhi cyclone) prevailed in the eastern AS invoked a suitable condition for phytoplankton bloom. Other TC found to be less provocative either due to less intensity, origination region or the unsuitable condition. Thereby, gap-free reconstructed daily satellite-derived data efficiently investigates the response of bio-geophysical parameters during cyclonic events. Moreover, this study sensitised that though several TC strikes the AS, only two could impact phytoplankton productivity and SST found to highly consistent with the chl- $a$ variability during the cyclone passage.
\end{abstract}

\section{INTRODUCTION}

The unusual physical dynamics such as tropical cyclone (TC) triggers the biogeochemical properties present in the ocean, which disturbs the distribution and dynamics of phytoplankton (Lin, 2012; Wang \& Zhao, 2008). Tropical cyclone passage on the sea causes two significant impacts that are generally encountered, first and foremost is intense wind and later is the sizeable freshwater discharge due to heavy rains near the shore (Corredor-Acosta et al, 2018). Most importantly during TC, the ocean faces fluctuation in the physical properties like cooling of sea surface temperature (SST) caused by vertical mixing of the water column (i.e. upwelling) (Lin 2012; Subrahmanyam et al, 2002). Such episodic events could bring more deep-seated nutrients to the upper surface that might induce the favourable conditions for certain phytoplankton types (Subrahmanyam et al, 2002). Therefore, TC passages profoundly influence phytoplankton production (Bharathi and Sarma, 2019). Most of the existing studies carried out in the Arabian Sea (AS) and the Bay of Bengal (BoB) highly focus on the dynamics of chlorophyll-a concentration (chl-a) (a proxy of phytoplankton biomass) variability because it is the primary pigment present in the phytoplankton and also principal identifying constituent through optical remote sensing (Prasanna Kumar et al, 2010; Chen et al, 2013). The Satellite-based ocean colour observation helps to continuously monitor the phytoplankton production in terms of chlorophyll-a concentration (Prasanna Kumar et al, 2007; IOCCG 2014). Most notably, satellite ocean colour observation has become a better tool to investigate the distribution phytoplankton blooms as it provides better spatial coverage on a large scale and temporal resolution (Moisan et al. 2012). Especially during a tropical cyclone, it is very challenging to conduct in-situ measurements, so satellite-based observation is efficient in terms of continuous data and costeffective (Taylor et al, 2013). Despite merits, a significant constraint usually undergone on satellite observation is data loss due to heavy cloud cover at the time of cyclone passage (Shropshire, Li, and He 2016). This limitation can be overcome by reconstructing the data using DINEOF method which helps to keenly observe the changes in geophysical variables (Rebekah, Inamdar, and Gedam 2019; Jayaram et al, 2018; Beckers and Rixen 2003).

In this study, we concentrate on how the cyclonic events impact the phytoplankton distribution in the Arabian Sea. To investigate this, we have taken 31 cyclone events occurred in the Arabian Sea over the past 16 years (2003-2018). We acquired freely available cyclone track data from IMD for conducting our study. To clearly understand the response of chl- $a$ to the cyclonic event, the temporal datasets includes precyclone and post-cyclone periods are taken into account. The data used for analysis are (1) chlorophyll-a concentration data from MODIS Aqua (2) sea surface temperature data from MODIS Aqua (3) Wind data from IMD. The paper is organised as follows: study area and cyclone information in Section 2, data methods are introduced in Section 3. The reconstruction of chl-a data, estimation chl- $a$ variability during the cyclonic events and comparison with SST and wind are discussed in Section 4. Finally, Section 5 summarises the conclusion. 


\section{STUDY SITE AND CYCLONIC EVENTS}

The Arabian Sea, the north eastern part of the Indian Ocean is a semi-enclosed basin partially covered by land located in the northern part of the Indian Ocean bounded within $43^{\circ} \mathrm{E}$ to $79^{\circ} \mathrm{E}$ longitude and $6^{\circ} \mathrm{N}$ to $30^{\circ} \mathrm{N}$ latitude. This region experiences a unique seasonal reversal wind pattern due to monsoon effects which support the biological productivity (Prasanna Kumar et al, 2010). Owing to this, AS is considered to be an extremely complex oceanic basin, encompassing eutrophic upwelling, downwelling and oligotrophic stratified environments (Prasanna Kumar et al, 2010). A tropical cyclone in the AS usually occurs during spring (April-May) and fall (OctoberNovember). Most of the intense TC originates from $\mathrm{BoB}$ and often drives to the AS (Mangesh et al, 2016). These cyclonic events could be associated with the upwelling of available nutrients, and this process leads to trigger biological productivity. In the Arabian Sea, over 31 TC cases were reported from the year 2003-2018 shown in Figure 1. The minimum duration of cyclone in the AS is found to be one day and a maximum of up to two weeks.

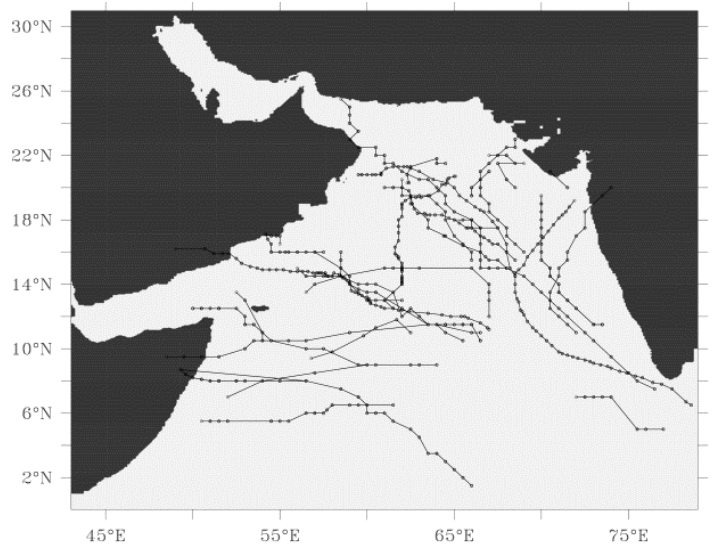

Figure 1. Tracks of tropical cyclones observed between 20032018 in the Arabian Sea.

\section{DATA AND METHODS}

\subsection{Satellite observation data}

The eight-day composite of chlorophyll-a concentration, sea surface temperature (SST) was acquired from MODIS-Aqua sensor which is a freely available data obtained from the NASA Ocean Color website (https://oceandata.sci.gsfc.nasa.gov/ MODIS-Aqua/). The spatial resolutions of these products are 4 $\mathrm{km} \mathrm{x} 4 \mathrm{~km}$, and it is the standard level 3 product. These products were acquired for the period from the year 2003-2018 with global coverage and further clipped to the latitude and longitude within range of the Arabian Sea from $0^{\circ} \mathrm{N}-31^{\circ} \mathrm{N}$ and $43^{\circ} \mathrm{E}-79^{\circ} \mathrm{E}$ respectively. Also, the wind data acquired from IMD cyclone track data.

\subsection{Algorithm of DINEOF method}

Gaps in the data during the passage of cyclone are relatively large due to cloud cover. The data loss during the cyclone is the major constraint because it would be a barrier to efficiently investigate the distribution of chl- $a$ at the time of cyclone track passage (Shropshire, Li, and He 2016). Though data loss could not be avoided, this limitation could be resolved by reconstructing the satellite-derived data using Data Interpolation Empirical Orthogonal Function (DINEOF) (Beckers and Rixen 2003). Missing data values in the chl- $a$ and
SST time series data can be filled through the DINEOF method. The DINEOF is an empirical orthogonal function based method developed by Becker and Rixen (2003) to reconstruct the missing data value efficiently without the need for any other additional information about the data. Necessarily, the input data should be log-transformed to avoid redundancy while reconstruction (Alvera-Azcárate et al, 2005; Jayaram et al, 2018). Before beginning the procedure, $10 \%$ of the original data is automatically kept aside by the model for crossvalidation (Beckers and Rixen 2003; A. Alvera-Azcárate et al, 2005). To start with, the log-transformed data is provided as input data with which the DINEOF first evaluate the percentage of missing data values and also the input spatio-temporal components. The input data is transformed into a matrix format, assuming temporal datasets as $\mathrm{T}$ which overpasses of the spatial coverage of Chl-a products over the same region and each overpass of Chl-a product have S pixels,. Therefore the matrix with the size of $\mathrm{T} x \mathrm{~S}$ is formed as

$$
X=\left(\begin{array}{cccc}
a_{1,1} & a_{1,2} & \ldots & a_{1, T} \\
a_{2,1} & a_{2,2} & \ldots & a_{2, T} \\
\vdots & \vdots & \vdots & \vdots \\
a_{S, 1} & a_{S, 2} & a_{S, 3} & a_{S, T}
\end{array}\right)
$$

Where $\mathrm{X}$ is the log-transformed data, $\mathrm{S}$ is the spatial pixel of an image and $\mathrm{T}$ is the temporal size of the data. Followed by the input data demeaning process is done, and the missing data values are assigned to zero. Then the Singular Vector Decomposition (SVD) process is carried out to calculate the EOF and the missing data are replaced with the obtained values. The formulation of SVD is

$$
X=U \sum V
$$

where $\mathrm{U}$ is the EOF, which indicates the spatial distribution mode of the matrix; $\mathrm{V}$ is the principle component (PC), which indicates the temporal distribution mode of the matrix; and $\sum$ contains the singular values of the matrix. The matrix could be accurately reconstructed using Eq. (2) with decomposed U, V, and $\sum$. This process is continued until the convergence standard achieved. After each EOF modes, the obtained values are crossvalidated with the original values to estimate the accuracy. The procedure, as mentioned earlier, is repeated until the percentage of error reduces when cross-validating with $10 \%$ of original values. The efficiency of the reconstructing the missing data majorly depends on the percentage of missing data and number of time series data (Alvera-Azcárate et al, 2016). Thereby, gapfree reconstructed satellite-derived data provides a better approach to study the response of such parameters during cyclonic events.

\section{RESULTS AND DISCUSSION}

\subsection{Reconstruction of missing data}

The reconstruction of chl- $a$ data obtained from MODIS-Aqua chl- $a$ products that cover the cyclonic events in the Arabian Sea is achieved using DINEOF method. The spatial data coverage of chl- $a$ data before and after the cyclone is shown in Figure 2 a and $2 \mathrm{~b}$. Form the figure; it is understood that the reconstructed chl- $a$ data provides more details about the chl- $a$ variability during and after the cyclone passage. On comparing the images before and after the reconstruction, it is found that the DINEOF method could fill missing data that covers the cyclone passage efficiently even though the data loss is high. For the detailed information about the data uncertainty, the percentage of data loss of all 31 cyclones track is shown in Figure 3. 


\begin{tabular}{|c|c|c|c|c|c|c|c|}
\hline SINO & Cyclone case & Start date & End date & $\begin{array}{l}\text { Duration in } \\
\text { days }\end{array}$ & $\begin{array}{l}\text { Surface wind in } \\
\quad(\mathrm{kt})\end{array}$ & Rate of change chl- $a$ & $\begin{array}{c}\text { Change in SST } \\
(\Delta \mathrm{SST})\end{array}$ \\
\hline 1 & ARB_2003_6 & $12 / 11 / 2003$ & $15 / 11 / 2003$ & 4 & 42 & 0.02 & -0.50 \\
\hline 2 & ARB_2004_1 & 05/05/2004 & $10 / 05 / 2004$ & 6 & 43 & -0.14 & -0.66 \\
\hline 3 & ARB_2004_3 & $10 / 06 / 2004$ & $13 / 06 / 2004$ & 4 & 29 & 0.02 & -0.69 \\
\hline 4 & ONIL & $30 / 09 / 2004$ & 03/10/2004 & 4 & 36 & 0.04 & -1.97 \\
\hline 5 & ARB_2004_9 & $02 / 11 / 2004$ & $07 / 11 / 2004$ & 6 & 26 & 0.00 & 0.23 \\
\hline 6 & AGNI & $29 / 11 / 2004$ & $02 / 12 / 2004$ & 4 & 37 & -0.01 & 0.21 \\
\hline 7 & ARB_2005_2 & $21 / 06 / 2005$ & $22 / 06 / 2005$ & 2 & 25 & 0.01 & -1.57 \\
\hline 8 & ARB_2005_6 & $14 / 09 / 2005$ & $16 / 09 / 2005$ & 3 & 25 & 0.02 & 1.04 \\
\hline 9 & ARB_2005_1 & $13 / 01 / 2006$ & $14 / 01 / 2006$ & 2 & 26 & -0.02 & 0.80 \\
\hline 10 & MUKDA & $21 / 09 / 2006$ & $24 / 09 / 2006$ & 4 & 39 & -0.01 & 0.97 \\
\hline 11 & GONU & $01 / 06 / 2007$ & 07/06/2007 & 7 & 55 & 0.00 & -1.34 \\
\hline 12 & ARB_2007_11 & $27 / 10 / 2007$ & $31 / 10 / 2007$ & 5 & 30 & 0.05 & -1.20 \\
\hline 13 & ARB_2007_12 & $01 / 11 / 2007$ & $01 / 11 / 2007$ & 1 & 25 & 0.01 & -0.31 \\
\hline 14 & ARB_2008_2 & 05/06/2008 & 06/06/2008 & 2 & 26 & 0.00 & 0.00 \\
\hline 15 & ARB_2008_6 & $19 / 10 / 2008$ & $22 / 10 / 2008$ & 4 & 32 & -0.04 & -0.01 \\
\hline 16 & PHYAN & 09/11/2009 & $11 / 11 / 2009$ & 3 & 29 & 0.09 & -2.84 \\
\hline 17 & BANDU & $19 / 05 / 2010$ & $22 / 05 / 2010$ & 4 & 32 & 0.02 & -1.25 \\
\hline 18 & ARB_2011_2 & $11 / 06 / 2011$ & $12 / 06 / 2011$ & 2 & 23 & 0.01 & -1.62 \\
\hline 19 & KEILA & $29 / 10 / 2011$ & $04 / 11 / 2011$ & 6 & 26 & 0.03 & -1.81 \\
\hline 20 & ARB_2011_8 & $06 / 11 / 2011$ & $10 / 11 / 2011$ & 5 & 30 & 0.00 & 0.51 \\
\hline 21 & ARB_2011_9 & $26 / 11 / 2011$ & $01 / 12 / 2011$ & 6 & 27 & 0.00 & -0.84 \\
\hline 22 & MURJAN & $22 / 10 / 2012$ & $26 / 10 / 2012$ & 5 & 28 & 0.00 & -0.16 \\
\hline 23 & ARB_2012_5 & $22 / 12 / 012$ & $24 / 12 / 2012$ & 3 & 27 & 0.00 & 0.46 \\
\hline 24 & ARB_2013_6 & $08 / 11 / 2013$ & $11 / 11 / 2013$ & 4 & 29 & 0.00 & -0.22 \\
\hline 25 & NANAUK & $10 / 06 / 2014$ & $14 / 06 / 2014$ & 5 & 40 & 0.01 & -0.30 \\
\hline 26 & NILOFAR & $25 / 10 / 2014$ & $31 / 10 / 2014$ & 6 & 60 & 0.05 & -1.42 \\
\hline 27 & ASHOBAA & $07 / 06 / 2015$ & $12 / 06 / 2015$ & 6 & 36 & -0.08 & -0.07 \\
\hline 28 & ARB_2016_2 & $27 / 06 / 2016$ & $29 / 06 / 2016$ & 3 & 25 & 0.01 & -1.87 \\
\hline 29 & ARB_2016_10 & $17 / 12 / 2016$ & $18 / 12 / 2016$ & 2 & 24 & 0.01 & 0.17 \\
\hline 30 & OCKHI & $30 / 11 / 2017$ & $05 / 12 / 2017$ & 6 & 60 & 0.19 & -3.03 \\
\hline 31 & LUBAN & $06 / 10 / 2018$ & $15 / 10 / 2018$ & 10 & 48 & 0.04 & -1.56 \\
\hline
\end{tabular}

Table 1. Summary of 31 cyclone cases occurred in the Arabian Sea from 2003 to 2018

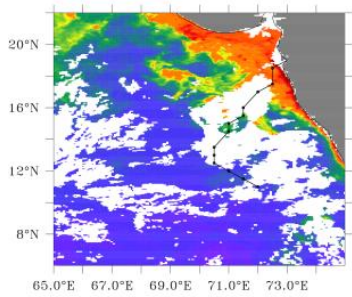

(a)

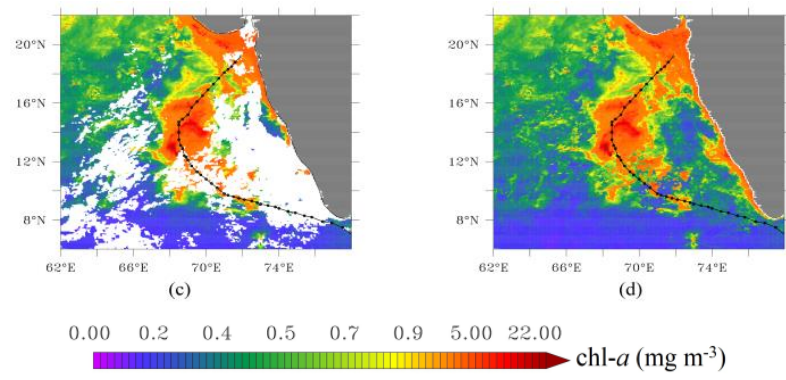

Figure 2. (a) The spatial coverage of chl- $a$ (a) and (c) before (b) and (d) after reconstruction Phyan and Ockhi cyclone. The black line in the image is the cyclone track.

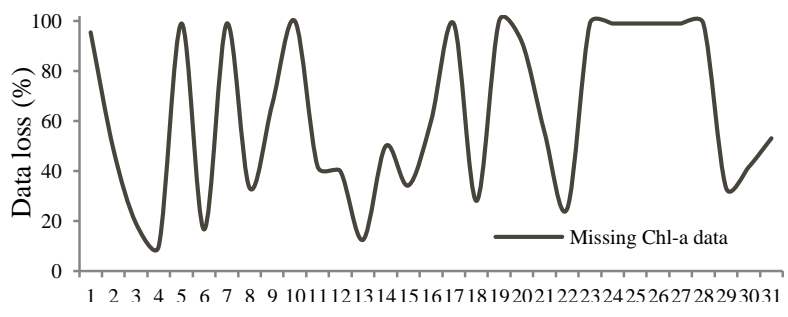

Figure 3. Percentage of uncertainty in the MODIS Aqua chl- $a$ data acquired during the cyclonic events. The cyclone cases are specified in Table 1 in ascending order as per the year occurred.

\subsection{Cyclone induced phytoplankton bloom}

The mesoscale variability of chl- $a$ and bloom trigger due to cyclonic event is examined using reconstructed chl- $a$ data. For an in-depth understanding of chl- $a$ variability due to cyclone, a total of 31 cyclone cases occurred in the AS from 2003-2018 is taken for analysis. Cyclone track data from IMD is used to extract corresponding chl- $a$ concentration on each transit point for all 31 cyclone cases under three stages (pre, during and post-cyclone). Through reconstructed chl- $a$, the above extraction process is efficiently achieved. On comparing the 31 
cyclone cases, it is found that only in few cyclone cases could initiate phytoplankton blooms even though the intensity is high. In Figure 4, only two cyclones (Phyan and Ockhi) could induce phytoplankton bloom compared to other cases. Variability of chl- $a$ during phayan pre-cyclone stage ranges from 0.1 to $1 \mathrm{mg}$ $\mathrm{m}^{-3}$ and during post-cyclone ranges from $4-8 \mathrm{mg} \mathrm{m}^{-3}$. Followed by the variability of Ockhi cyclone during pre -cyclone stage ranges from $0.1-0.3 \mathrm{mg} \mathrm{m}^{-3}$ and during post-cyclone phase ranges from $0.7-1.5 \mathrm{mg} \mathrm{m}^{-3}$. On observing these two cases in detail, it clearly shows the relative extreme increase of chl- $a$ concentration (i.e. bloom) from pre cyclone to the post-cyclone stage (highlighted in the black box in Figure 4).

Moreover, one similarity observed in both the cyclone cases is that the cyclone transit originated in the eastern-AS and terminated in the same eastern AS. The rate of change of Phyan and Ockhi are 0.09 and 0.19, respectively. Other 29 cases show very less and even negative chl- $a$ rate of change due to the nonfavourable condition (i.e. less nutrient), which reduces the upwelling process

\subsection{Comparison with SST and wind intensity}

Sea surface temperature data acquired from the MODIS-Aqua and wind intensity data from IMD is compared with the extracted chl- $a$ from the reconstructed data based on the cyclone passage information for all 31 cases. Further, the data is applied to investigate the associated cyclone induced SST cooling and wind intensity responsible for a phytoplankton bloom. Figure 5 (a) illustrates the rate of change (ROC) of chl-a observed in all 31 cyclone cases and the corresponding change in SST. The ROC of chl- $a$ highly coincides with the $\Delta$ SST. It can be noted that the cooling response induced by Phyan and Ockhi case is $-2.84{ }^{0} \mathrm{C}$ and $-3.03^{0} \mathrm{C}$, respectively. However, $\Delta \mathrm{SST}$ in other cases is mostly around $\sim+0.4^{\circ} \mathrm{C}$ to $\sim-1.5^{\circ} \mathrm{C}$.

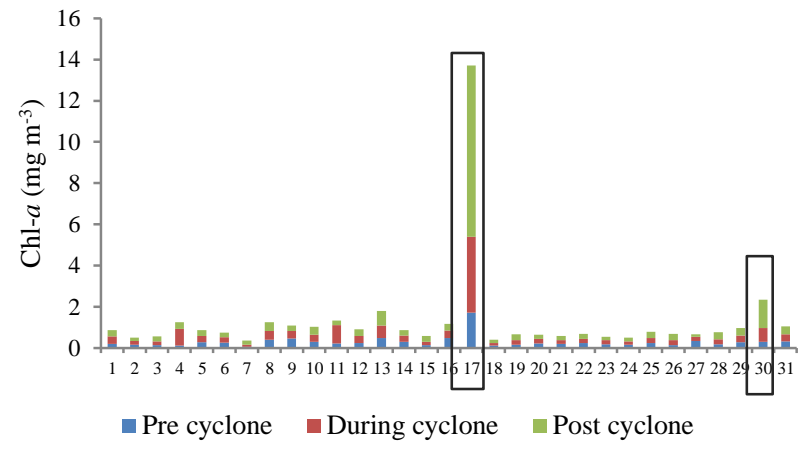

Figure 4. Observation of chl- $a$ before, middle and after the passage of 31 cyclone tracks. The cyclone cases information is specified in Table 1 in ascending order as per the year occurred.

In addition, when comparing with the wind intensity (shown in Figure 5 (b)), it can be observed that it play a partial role on chl- $a$ variability because in some cases under the serial number (refere Table 1) 2, 12 and 26 (ARB_2004_1, ARB_2007_11 and NILOFAR respectively). However, the wind intensity is high; it could not influence the chl- $a$ compared to SST. On the whole, the $\Delta$ SST shows consistency with the chl- $a$ ROC. Besides one similarity found on both the cyclone cases is that the cyclone originated and terminated in the eastern part of the Arabian Sea. This suggests that, though AS has encounters many numbers of cyclone cases even with the high intense wind, it has contributed only little to the biological productivity. The impact of cyclone induced phytoplankton bloom is less compared to seasonal variability in the AS

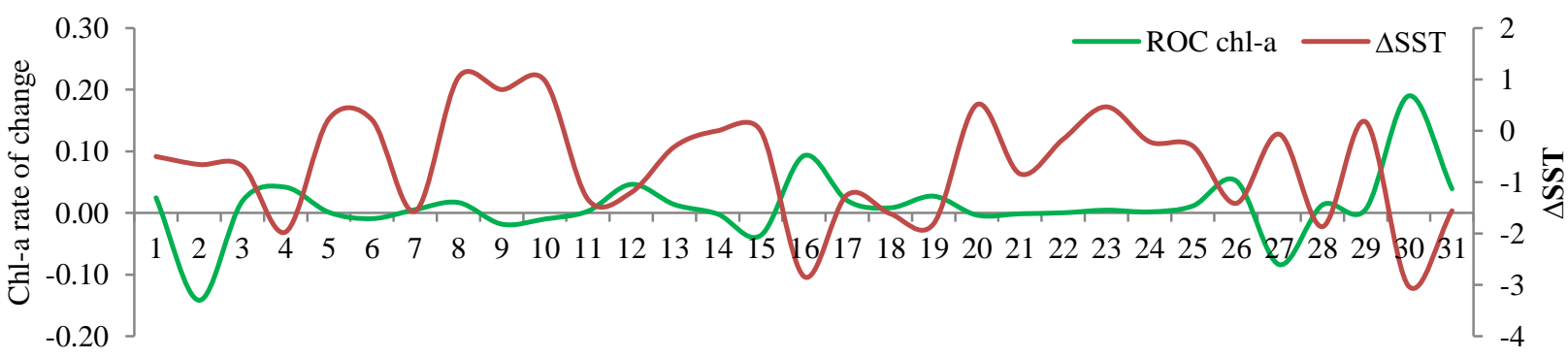

(a)

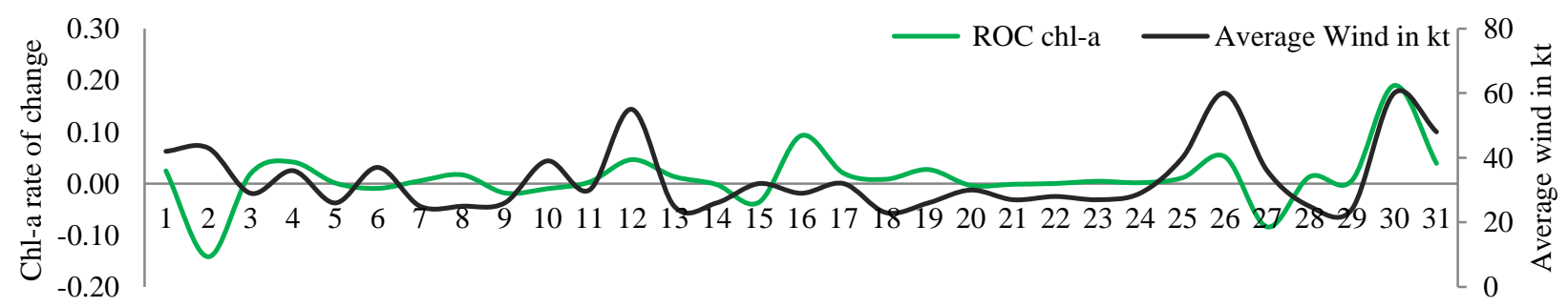

(b)

Figure 5. Comparison of (a) SST cooling response and (b) wind intensity with the chl- $a$. (The cyclone cases information is specified in Table 1 in ascending order as per the year occurred). 


\section{CONCLUSION}

Using the reconstruction of chl- $a$ data, this study investigates the cyclone induced phytoplankton bloom in the Arabian Sea for 16 years (2003-2018). The reconstructed data gives better accuracy and highly supports to observe chl- $a$ variability during the cyclone passage. Totally 31 cyclone cases have been observed in this study. It was found that over 31 cyclone cases, only two cases could induce phytoplankton bloom in the Arabian Sea. Even the prominent cyclone cases, i.e. Nilofar, could not be able to induce bloom. This is because the nutrient upwelling during the cyclone is the cause for the phytoplankton bloom, and it could be identified through the SST cooling range. Indeed, the observation also supports this scenario; the corresponding SST cooling range found in the cyclone passage is highly consistent with the chl- $a$ proliferation. The overall study demonstrates the biological response of the Arabian Sea during the passage of a cyclone. In summary, the potential use of gap-filled chl-a to investigate its response to the cyclone occurred in the AS over 16 years is highlighted.

\section{ACKNOWLEDGEMENTS}

The authors thank NASA Ocean Color (https://oceancolor.gsfc.nasa.gov) for providing the open source chlorophyll-a concentration data and Indian Meterological Department for providing open source cyclone track data.

\section{REFERENCES}

Alvera-Azcárate, A., A. Barth, M. Rixen, and J. M. Beckers. 2005. "Reconstruction of Incomplete Oceanographic Data Sets Using Empirical Orthogonal Functions: Application to the Adriatic Sea Surface Temperature." Ocean Modelling 9 (4): 325-46. https://doi.org/10.1016/j.ocemod.2004.08.001.

Alvera-Azcárate, Aida, Alexander Barth, Gaëlle Parard, and Jean Marie Beckers. 2016. "Analysis of SMOS Sea Surface Salinity Data Using DINEOF." Remote Sensing of Environment 180: 137-45. https://doi.org/10.1016/j.rse.2016.02.044.

Beckers, J. M., and M. Rixen. 2003. "EOF Calculations and Data Filling from Incomplete Oceanographic Datasets.” Journal of Atmospheric and Oceanic Technology 20 (12): 1839-56. https://doi.org/10.1175/1520-

0426(2003)020<1839:ECADFF>2.0.CO;2.

Bharathi, M. D., and V. V.S.S. Sarma. 2019. "Impact of Monsoon-Induced Discharge on Phytoplankton Community Structure in the Tropical Indian Estuaries." Regional Studies in $\begin{array}{lll}\text { Marine } & \text { Science } & 31 \text { : }\end{array}$ https://doi.org/10.1016/j.rsma.2019.100795.

Corredor-Acosta, Andrea, Carmen E. Morales, Robert J.W. Brewin, Pierre Amaël Auger, Oscar Pizarro, Samuel Hormazabal, and Valeria Anabalón. 2018. "Phytoplankton Size Structure in Association with Mesoscale Eddies off CentralSouthern Chile: The Satellite Application of a Phytoplankton
Size-Class Model." Remote Sensing $10 \quad$ (6). https://doi.org/10.3390/rs10060834.

Dierssen, H. M. 2010. "Perspectives on Empirical Approaches for Ocean Color Remote Sensing of Chlorophyll in a Changing Climate." Proceedings of the National Academy of Sciences 107 (40): 17073-78. https://doi.org/10.1073/pnas.0913800107.

Jayaram, Chiranjivi, Niraj Priyadarshi, Jonnakuti Pavan Kumar, Tata Venkata Sai Udaya Bhaskar, Devendar Raju, and Ajith Joseph Kochuparampil. 2018. "Analysis of Gap-Free Chlorophyll-a Data from MODIS in Arabian Sea, Reconstructed Using DINEOF." International Journal of $\begin{array}{llll}\text { Remote } & \text { Sensing } & 39 & \text { (21): }\end{array}$ https://doi.org/10.1080/01431161.2018.1471540.

Lin, I. I. 2012. "Typhoon-Induced Phytoplankton Blooms and Primary Productivity Increase in the Western North Pacific Subtropical Ocean.” Journal of Geophysical Research: Oceans 117 (3). https://doi.org/10.1029/2011JC007626.

Mangesh, Gauns, Kurian Siby, Shenoy M. Damodar, Naik Hema, and S. W.A. Naqvi. 2016. "Cyclone Phyan-Induced Plankton Community Succession in the Coastal Waters off Goa, India." Current Science 111 (6): 1091-97. https://doi.org/10.18520/cs/v111/i6/1091-1097.

Moisan, Tiffany a H, Shubha Sathyendranath, Heather a Bouman, Goddard Space, and Wallops Island. 2012. "Ocean Color Remote Sensing of Phytoplankton Functional Types." Remote Sensing of Biomass - Principles and Applicaiton, 10122. https://doi.org/DOI: 10.5772/17174.

Prasanna Kumar, S., Raj P. Roshin, Jayu Narvekar, P. K. Dinesh Kumar, and E. Vivekanandan. 2010. "What Drives the Increased Phytoplankton Biomass in the Arabian Sea?" Current Science 99 (1): 101-6.

Rebekah, S, A B Inamdar, and Shirish S Gedam. 2019. "LongTime-Scale Investigation Of Phytoplankton Biomass Through Reconstructed Chlorophyll-A Data Using Dineof Method Indian Institute of Technology Bombay , Mumbai , Maharashtra , India - 400076.” IGARSS 2019 - 2019 IEEE International Geoscience and Remote Sensing Symposium, 7995-98.

Shunmugapandi, Rebekah, Arun B. Inamdar, and Shirish Kumar Gedam. 2020. "Long-Time-Scale Investigation of Phytoplankton Communities Based on Their Size in the Arabian Sea." International Journal of Remote Sensing 00 (00): 1-18. https://doi.org/10.1080/01431161.2020.1714785.

Shropshire, Taylor, Yizhen Li, and Ruoying He. 2016. "Storm Impact on Sea Surface Temperature and Chlorophyll a in the Gulf of Mexico and Sargasso Sea Based on Daily Cloud-Free Satellite Data Reconstructions." Geophysical Research Letters $43 \quad$ (23): 12,199-12,207. https://doi.org/10.1002/2016GL071178. 
Subrahmanyam, Bulusu, K. H. Rao, N. Srinivasa Rao, V. S. N. Murty, and Ryan J. Sharp. 2002. "Influence of a Tropical Cyclone on Chlorophyll-a Concentration in the Arabian Sea." Geophysical Research Letters 29 (22): 22-1-22-24. https://doi.org/10.1029/2002g1015892.

Taylor, Marc H., Martin Losch, Manfred Wenzel, and Jens Schröter. 2013. "On the Sensitivity of Field Reconstruction and Prediction Using Empirical Orthogonal Functions Derived from Gappy Data." Journal of Climate 26 (22): 9194-9205. https://doi.org/10.1175/JCLI-D-13-00089.1.

Wang, Dongxiao, and Hui Zhao. 2008. "Estimation of Phytoplankton Responses to Hurricane Gonu over the Arabian Sea Based on Ocean Color Data." Sensors 8 (8): 4878-93. https://doi.org/10.3390/s8084878.

IOCCG. 2014. "Phytoplankton Functional Types from Space." Reports and Monographs of the International OceanColour Coordinating Group, no. 15: 15. 